\title{
Listening to our Environments: Soundscape Analysis in Geographic Research
}

\author{
Mark J Sciuchetti Jr \\ Assistant Professor of Geography, Jacksonville State University, Jacksonville, Alabama
}

^Corresponding author: Mark J. Sciuchetti Jr., Assistant Professor of Geography, Jacksonville State University, Jacksonville, Alabama; Email: msciuchetti@jsu.edu

Received: May 04, 2020; Accepted: May 10, 2020; Published: May 17, 2020

Keywords: Acoustic ecology, Biogeography, Geography, Marine habitats, Soundscapes, sound ecology, soundscape analysis

\section{Introduction}

The study of sound and the soundscape is a burgeoning arena that is taking hold in the fields of earth science research. The sensory experiences of our studies often disregard the sonic elements of our environments. The visual is privileged over the other senses, which means that we miss an important aspect of our surroundings that can participate in our research [1]. I argue that we need to incorporate more of our sensory experiences. I will discuss the history of the field of sound/soundscape research in geography, focusing on the introduction of sound studies into cultural geography. I will explore the development of sound studies into various branches of geography and the new methods that are being utilized for studying ecosystems, specifically marine ecosystems. I will conclude with some thoughts on the use of soundscapes to benefit our research and its usefulness in our future endeavors.

\section{Soundscapes in Geography}

The work of sound studies and acoustic ecology began with R. Murray Schafer's [2], establishment of soundscape studies at Simon Fraser University. In the geographic literature that examines sound, scholars have established a foundation from the landscape tradition $[3,4]$. The word landscape is often used in reference to landscape painting, but is geographically a portion of the earth's surface, which includes all the natural and human entities that fall within that landscape. The artistic creation is simultaneously a depiction of the already known as well as a place to reimagine the landscape $[3,5]$. Landscape as a cultural production is important to the depiction of place and the intricate detail that is provided in the painting of a place. The method to landscape in geography, through its many different approaches, opened the way for geographers of sound to explore the role of sound and the soundscape as a way of hearing a portion of the natural and cultural environment. Soundscapes are ephemeral and are ever changing; they are not as permanent as the visual of the landscapes and can provide insight into the reconstruction of place and the environment. The ephemerality of the soundscapes is often overlooked. Sound can bring attention of the ephemeral to the experience of the landscape where the visual of the landscape is more material and formal. The soundscape tradition in geography draws from the works of landscape geographers and incorporates the scholarship of sound studies, beginning with the soundscape [6-8]. According to Schafer [2], the soundscape is a merger of the word landscape and sound that focuses on the sounded aspect of an environment beyond just traditional ideas of music and musical performance. The soundscape is the total sound environment that can be perceived in any given moment in any place and includes three types of sounds: (1) geophony, natural sounds such as the wind, water, and earth, (2) biophony, sounds of animals such as birds, whales, and insects, and (3) anthrophony, humanly produced sounds[2, 9-10]. His book, The Soundscape: Our Sonic Environment and the Tuning of the World, provides a starting place to discuss how individuals identify sound marks, or sounds from a place that signify a particular environment, within a soundscape and use them to evoke place. Schafer discusses the importance of hearing as a special sense that is often overlooked, but one that provides important information that can tell us about society and the environment. Recently, sound artists have discussed the importance of the sonic landscape and the role of environmental sounds in forming our sense of place and understanding our environments [11]. According to the sound artists interviewed by Bianchi and Manzo [11], developing a "counterpoint to visual thinking" we sharpen our other senses and increase our ability to think with our ears. The ways in which individuals hear places and locate their sense of place is directly affected by the sounds of the places they inhabit (Bianchi and Manzo, 2016)-11. Dr. Ximena Alarcon, a sound artist specializing in migratory spaces that are in between the departures and destinations of a traveler, argues that as individuals move their "memory and senses look for references that help [them] to accept and understand a new place" [11]. Individuals listen for acoustical markers of places as a way of describing new places as compared to their old environments. Sound is now recognized as an important means to comprehend the world. As such, further study of sound and their connections to a place is a timely pursuit. Building upon soundscape studies provides a link between geography and music. The sense of hearing and the information it provides offers building blocks for examining the environment [12]. Lily Kong has argued that geographers should be exploring at sound to study society and the environment because“...just as [music] is a 
medium for conveying myriad experiences, music is also the outcome of environmental experience. Musicians write their music as a consequence of their experiences. Music can thus be said to possess a dual structure: as both the medium and the outcome of experience, it serves to produce and reproduce social systems" [12-14] contend that sound contributes to human interactions with the environment. Sound had been studied for its ability to change one's perception of the natural world and an individual's imagined creation of places through feelings, emotions, and atmospheres [2]. Soundscapes were also an early concern of geographers, including George Revill [15] and Lily Kong [12], who studied sound within the landscape to explain what was considered pleasant in place and what counted as noise or being out of place or disruptive to an environment. The concept of soundscape provided geographers a way to study human environments as places [13]. Researchers can use this sonic knowledge of place to consider how individuals and communities reflect and inhabit their places and interact with their environments. Another way to study sound is to focus on listening. "Listening points to a theorization of place and people as intertwined as sound passes through and into the body" [16]. Scholars need to reconsider the human-environment relationship, there are many sounds in place and many interpretations of that place. Everyone experiences sound differently and they listen differently, therefore individuals' perceptions of sound can be read differently into a collected whole articulating meaning in place and the stability and health of an environment [16].

\section{Soundscape and Ecosystem Analysis}

The recording of the soundscape to examine the sounds of an environment can add to our studies of the environment beyond the study of place or our traditional studies of ecosystems measurement and biodiversity. According to Jachowski, soundscape analysis not only supports a qualitative analysis of place but offers researchers a way to examine ecosystem health through sound. In the past, traditional ecological assessment such as soil analysis, worm density surveys, and vegetation surveys, have been key in examining ecosystem health. Present studies have taken from the cultural geography of sound the importance of incorporating sound into our research. Soundscape ecology, as part of the development in sonic geography, provides a way to examine environmental sounds to assess ecosystem health. One method in the measurement of ecosystem health is taking recordings that are comprised of biophonic, anthrophonic, and geophonic sounds. This process incorporates all elements of a site, offering a more holistic view of a study area [10]. The biophonic data that is collected from a study area can be an indicator of ecosystem health, just as soil analysis, tagging, or vegetation can be used to examine that systems health. As Krause [10] examines, soundscape recordings can reveal changes in the environment. Recordings taken over multiple years of the same site offer a way to study alterations in the environment. Collecting the sound data of a place can help researchers explore developments such as the decline in some species or the movement of different species to or from other areas. The anthrophonic sounds are also useful when collected as part of the soundscapes. These sounds in the collective soundscape established the role that ambient anthrophonic sounds have on the non-human natural environment $[17,18]$. The workings of the soundscape extend beyond the terrestrial world for the study of ecosystem health and habitat restoration. Soundscape ecology offers new avenues for the study of underwater habitats and the effects of anthropogenic sounds on marine life. Soundscapes have been used for some time to analyze the inhabitants of a marine ecosystem $[17,19]$. Soundscape recording has been a more efficient way to explore biodiversity, ecosystem health, and environmental degradation because sound contains a plethora of data. Sound recording helps with the issues of data collecting in a marine environment. For example, who studying the population of mussels, fish, and other invertebrates that traditional methods of catch and release, tagging, and observation can be time consuming, costly, and difficult. Sound recording requires a few recording devices, microphones, and if equipment is available remote monitors. Once the data is recorded and either sent via wireless connections or collected from memory cards in the field, that data can then be displayed in a spectrogram. Depending on the memory sources, data can be collected for days and months constantly, providing researchers a vast amount of data for an ecosystem; data can also be easily collected over periods of years and compared. The use of soundscape recordings in the fields of biogeography, marine biology, soundscape ecology, and other earth sciences can provide new methods of examining ecosystem health and habitation as well as biodiversity through listening to the places we are studying. The availability and accessibility of recording equipment has helped scientists and citizen scientists with the collection of vast amounts of data. With the increase in the availability of tools for data collection, a push for more analysis tools have come to the fore as the listener and the visual and auditory analysis of a spectrogram is not enough for the mass amounts of data we have from the field. The tools for the analysis of soundscapes and acoustic habitats have grown steadily. In the statistical software, R, there now exists packages designed for the purpose of soundscape ecology [20]. These soundscape packages are helpful in analyzing spectrograms for the acoustic complexity, diversity, and evenness of a habitat. The packages also assist in differentiating between signals such as different species of birds and marine life, which assists in the analysis of the number of species in a location.

\section{Conclusion}

The future of research in geography, ecosystem health, and marine habitats will continue to benefit from the use of soundscape analysis. As I have discussed above, soundscapes provide another dimension to our traditional research that not only deepens our knowledge of our study sites, but it can also provide a more holistic view of our research areas. Using field recordings, researchers can evaluate the impacts of humans and human sounds on fish habitats and various fish species. The soundscapes of underwater habitats contain much more information than can often be collected by traditional means. Examining the sounds of an underwater system exposes the impacts of human generated sound on the environment. It can also display the biodiversity of a site that often cannot be visually examined [18]. The sounds that are produced in or around a marine ecosystem can cause changes in that system. The study of the sound recordings can help researchers better understand the role of sound on species development such as the productivity and growth of mussels, the 
health of sponge habitats, and the sounds of tropical habitats based on acoustic signals[17, 21]. In the future as scholars and researchers we need to look toward using soundscapes for analysis of ecosystems, habitats, and human-environment relationships. We can also use soundscapes as a method to involve our communities and collect more data from citizen scientists, by getting more people involved and aware of their environments. The new recording methods and analysis of soundscapes will shed new light on our research of ecosystems health and assist in the preservations of those environments. As researchers, we might take these methods to answer questions such as: what causes change in an ecosystem from year to year? Does sound affect marine life, and can it cause the degradation of a marine habitat? Do anthropogenic sounds influence or change a marine environment and influence biological life development? Can we track the changes in a habitat to see the influence of severe weather on an ecosystem and will these new methods provide accurate results beyond our traditional methods? Finally, will soundscape data and analysis help scholars and citizens create awareness, preservation and restoration of marine habitats?.

\section{References}

1. Atkinson R (2007) Ecology of Sound: The Sonic Order of Urban Space. Urban Studies 44: 1905-1917.

2. Schafer RM (1993). The Soundscape: Our Sonic Environment and the Tuning of the World. Rochester: Destiny Books.

3. Cosgrove D (1985) Prospect, Perspective and the Evolution of the Landscape Idea. Transactions of the Institute of British Geographers 1: 45-62.

4. Feld S, Basso KH (1996). Senses of place. Santa Fe: School of American Research Press.

5. Duncan J (1995) Landscape geography, 1993-94. Progress in Human Geography 19: 414-422.
6. Hilmes M (2008) Foregrounding sound: new (and old) directions in sound studies. Cinema Journal 48: 115-117.

7. Pinch T, Bijsterveld K (2012) The Oxford handbook of sound studies. New York: Oxford University Press.

8. Polli A (2012). Soundscape, sonification, and sound activism. AI \& SOCIETY 27: 257-268.

9. Truax B (1992). Composing with Time-Shifted Environmental Sound. Leonardo Music Journal 2: 37-40.

10. Krause B (2016). Wild Soundscapes. New Haven: Yale University Press.

11. Bianchi FW, Manzo VJ (2016) Environmental sound artists: In their own words. New York: Oxford University Press.

12. Kong L (2006) Music and moral geographies: Constructions of "nation" and identity in Singapore. GeoJournal, 65: 103-111.

13. Leyshon A, Matless D, Revill G (1995) The Place of Music. Transactions of the Institute of British Geographers 20: 423-433.

14. Matless D (2005) Sonic geography in a nature region. Social \& Cultural Geography 6: 745-766.

15. Revill G (2000). Music and the Politics of Sound: Nationalism, Citizenship, and Auditory Space. Environment and Planning D: Society and Space 18: 597-613.

16. Duffy M, Waitt G (2011) A Method for Listening to Place, 18.

17. Butler J, Stanley JA, Butler MJ (2016). Underwater soundscapes in near-shore tropical habitats and the effects of environmental degradation and habitat restoration. Journal of Experimental Marine Biology and Ecology, 479: 89-96.

18. Coquereau L, Lossent J, Grall J, Chauvaud L (2017). Marine soundscape shaped by fishing activity. Royal Society Open Science.

19. Harris SA, Radford CA (2014) Marine soundscape ecology. INTER-NOISE and NOISE-CON Congress and Conference Proceedings. Institute of Noise Control Engineering pp. 5003-5011.

20. Villanueva Rivera LJ, Pijanowski BC (2018). Soundscape Ecology. CRAN.

21. Vazzana M, Celi M, Maricchiolo G, Genovese L, Corrias v, et al. (2016). Are mussels able to distinguish underwater sounds? Assessment of the reactions of Mytilus galloprovincialis after exposure to lab-generated acoustic signals. Comparative Biochemistry and Physiology 201: 61-70. [crossref] 